\title{
CONSIDERAÇÕES JURÍDICAS SOBRE OS EFEITOS PATRIMONIAIS NOS NOVOS MODELOS FAMILIARES: A QUESTÃO DAS FAMÍLIAS PLURAIS
}

\author{
Luciana Costa Poli ${ }^{1}$ \\ Aloísio Alencar Bolwerk ${ }^{2}$
}

\section{Resumo:}

O artigo suscita o debate jurídico acerca das famílias paralelas. Após indagar sobre a possibilidade ou não de atribuições de efeitos patrimoniais às entidades familiares estáveis e paralelas, o texto analisará a forma pela qual o Poder Judiciário tem enfrentado o tema. $\mathrm{O}$ trabalho questiona a necessidade de reconhecimento de toda e qualquer unidade social que tenha caráter familiar, colocando em debate os desafios para o atendimento das demandas de todos os núcleos familiares. O estudo busca uma reflexão sobre o enfrentamento crítico, a complexidade e a interseção constante dos elementos que compõem o sistema do direito de família contemporâneo.

Palavras-chave: Famílias; Autonomia; Liberdade de escolha.

\section{LEGAL CONSIDERATIONS ON THE PATRIMONIAL EFFECTS IN THE NEW FAMILY MODELS: THE QUESTION OF PLURAL FAMILIES}

\begin{abstract}
:
The article debates about the parallel families. After raising questions about the possibility or not of assigning patrimonial effects to stable and parallel family entities, the text will analyze how the Judiciary has faced this issue. The work questions the need for recognition of any social unit that has a family character, putting in debate the challenges of to meet in an equal way the demands of all family nuclei. The study seeks a reflection on the critical confrontation, the complexity and the constant intersection of the elements that compose the contemporary family law system.
\end{abstract}

Keywords: Families; Autonomy; Freedom of choice.

\section{INTRODUÇÃO}

\footnotetext{
1 Pós-Doutoranda pela UNESP (Bolsista a CAPES/PNPD). Doutora em Direito Privado pela Pontifícia Universidade Católica de Minas Gerais. Mestra em Direito e Instituições Políticas pela Universidade FUMEC/MG. Professora Adjunta do Curso de Direito da PUC/MG.

${ }^{2}$ Possui graduação em Direito e estudos pós-graduados em Direito Público. Mestre em Direitos Difusos e Coletivos pela Universidade Metropolitana de Santos e Doutorado em Direito Privado pela Pontifícia Universidade Católica de Minas Gerais. Professor Adjunto I da Fundação Universidade Federal do Tocantins e da Faculdade de Ciências Jurídicas de Paraíso do Tocantins, onde também exerço a função de Coordenador do Curso de Direito.Tenho experiência na área de Direito, com ênfase em Hermenêutica Jurídica, Direito Civil, Direito Constitucional e Direito das Relações de Consumo, atuando principalmente nos seguintes temas: métodos hermenêuticos de interpretação do Direito, princípios constitucionais, Direitos Humanos e Direitos Fundamentais, responsabilidade civil e regulação jurídica da publicidade.
} 
Qualquer análise metodológica sobre as novas propostas de entidades familiares deve levar em conta a fluidez e a velocidade das relações interpessoais na pós-modernidade. São transformações sociais das quais o Direito não pode virar as costas, ainda que não consiga acompanhar o acelerado ritmo delas; e nem precisa, pois, esta tarefa subsiste, indubitavelmente, ao trabalho hermenêutico que requer atividade interpretativa de adequação e de flexibilização, de modo a desdobrar os efeitos normativos afinados com o novo paradigma de família que vem sendo disseminado na sociedade Brasileira.

É de se notar que a restrição normativa da matéria prevista no conteúdo da Legislação Pátria leva a uma exegese limitada e restrita quanto ao conceito de entidade familiar. Todavia, a norma-padrão é apenas uma fonte do Direito, restando ao hermeneuta a interpretação analítica que culmina na integração dos casos em suas peculiaridades.

Esta atividade interpretativa que amplia o conceito de família se torna cada vez mais ascendente porque as entidades familiares e suas novas formatações são questões muito mais ligadas aos aspectos antropológicos e sociológicos do que jurídicos. Porém, o que ainda se verifica é uma incessante e exaustiva atuação do Estado a ditar enredos e projetos de formatação familiar. Definitivamente, desta atividade não deveria se ocupar, pelo menos não precipuamente. Mas a ingerência estatal termina por produzir regras limitadoras da autonomia da vontade naquilo que ela tem de mais singular, o exercício das liberalidades de escolhas de vida; anseios humanos tão atrelados a ordem puramente existencial.

Sob esta perspectiva interpretativa adaptada à pós-modernidade de uma sociedade aberta é que o presente artigo visa tecer comentários sobre as novas formatações familiares. A partir de metodologia axiológica, ou seja, em consonância com os valores sociais circundantes, é que se utilizará o método indutivo como ferramenta procedimental a ensejar adequação e mesmo flexibilização do conteúdo da norma geral ao caso concreto. A partir do viés inverso usado pela dedução, procura encaixar os contornos da lei às particularidades do fato.

Enquanto objetivo, a pesquisa defende a elasticidade do conceito de família, porém, não uma elasticidade desarrazoada, sem compromisso ou critério metodológico. Frisa-se, que o método aqui empregado - em razão de sua potencial plasticidade - é o indutivo porque é o que melhor se encaixa a proposta do pretenso trabalho.

A justificativa que sustenta a pesquisa é por conta do processo inverso que vem ocorrendo com o conceito e com a própria estrutura familiar em si, isto é, a excessiva 
ingerência Estatal provoca o engessamento legislativo e termina por petrificar a interpretação nos Tribunais. Tal situação passa a gerar, crescentemente, desconforto social na medida em que segrega, promove estigmas e constrói estereótipos familiares.

\section{OS NOVOS MODELOS FAMILIARES: AUTONOMIA DA VONTADE VERSUS INGERÊNCIA ESTATAL}

O modo como o Estado vem intervindo no direito de família - e quando se fala em Estado quer se incluir não só as leis, mas a postura interpretativa do judiciário, - não converge com a proposta de sociedade aberta, onde democracia e liberdade mantêm liame sintagmático e qualquer cerceamento aos projetos de escolha de vida importarão em afronta à própria democracia.

O exercício da democracia no ambiente de sociedade aberta não resulta somente de um processo de participação e inserção dos cidadãos no cenário político-governamental, mas também de processo de inclusão, de efetivo exercício no plano social que encontra amparo no caloroso direito de família. Ora, a esfera privada de realização também é locus onde as pessoas se destacam enquanto agentes transformadores, sujeitos de direito a reivindicar maior exercício das liberdades pessoais, encontrando na autonomia da vontade o fundamento direcionador e ao mesmo tempo conhecimento jurídico que se agrega ao patrimônio do Direito Civil a viabilizar o exercício destas liberdades. Indubitavelmente, pertence à autonomia o conteúdo do domínio emancipatório do homem. Sobre o princípio e sua significação,

\footnotetext{
O vocábulo autonomia vem do grego autos + nomos e significava independência, autodeterminação, o que é regido por leis próprias; direito de reger-se segundo leis próprias, em regime de liberdade e independência; faculdade de determinar as próprias normas de conduta, sem imposições de outrem. Etimologicamente, autonomia significa o poder de modelar por si - e não por imposição externa - as regras da própria conduta. Isto é, autonomia é a capacidade de governar-se com as próprias regras". (CABRAL, 2004, p. 84, grifo do autor).
}

A autonomia da vontade deriva dessa acepção etimológica, correspondendo a certa manifestação da liberdade de cada um dentro do campo jurídico. Não se confunde com autonomia privada, ainda que ambas possam apresentar sintonia jurídica, vez que esta gira em torno do poder de criação do agente que, a partir da esfera do direito, ou ainda dentro de determinada reserva 
legal, tem a liberdade/faculdade de se auto revestir por normas e comandos próprios, porém subordinadas àquelas impostas pela vontade da força estatal.

Ao seu turno, a autonomia da vontade afigura-se de forma subjetiva, a partir de comando cuja orientação é de ordem psicológica e denota o rumo a ser traçado e o sentido a ser atingido pela vontade do agente (AMARAL, 2006, p. 345). Como se vê, a autonomia da vontade caracteriza-se por ser uma vontade subjetiva do agente, de modo que ele tenha o poder-direito para elaborar o desenho de sua autodeterminação; já a autonomia privada assume critérios objetivos para sua composição, onde o agente tem o poder-direito de auto-regulamentação para arquitetar as normas internas e privatistas a lhe guiar, mas respeitando limites legais. O exercício desta auto-regulamentação fica bem assentado no direito das obrigações e contratuais, enquanto que a autodeterminação é possível ser externada quando das escolhas psicosubjetivas de projetos de vida feitas pelo sujeito livremente imerso em sua vontade declaradamente emancipada, a exemplo de decisões sobre matrimônio, filhos e aquisição de bens.

Em respeito à autonomia da vontade é que - e especialmente para o Direito Família ao contrário da criação de norma para cada situação estanque que se apresenta, a melhor opção é a figura do Estado mínimo, mediante disciplina restrita. Esta, com certeza, é a axiologia mais apropriada que o Estado poderia adotar diante de enredo volátil e tão eminentemente pertencente a ordem do "ser". À hermenêutica, restará a atividade interpretativa necessária a apurar caso a caso, vez que "A conformação da família contemporânea em muito difere do modelo oitocentista: patrimonial, hierarquizada, patriarcal. O conceito atual de família perpassa pela convivência pautada na solidariedade em função da afetividade representada por laços emocionais conjuntos" (FIUZA; AUTOR, 2015, p. 153).

Muitas são as interpretações sobre os novos modelos de família, descambando em sentidos diversos e que terminam por remeter para outras projeções que, por vezes, descaracterizam a essência das entidades familiares em si. Exemplo disso, são algumas propostas de famílias sociológicas ou parafamiliares. Estender o conceito de entidade familiar é o objetivo aqui pretendido, mas sem recair em rumos incertos e inseguros de interpretação. Nesta senda, acertada a ponderação de César Fiuza, que aponta para o conceito de família inserto na pós-modernidade:

O conceito de família hoje decorre do seguinte: família para a promoção do indivíduo, sua autonomia e pleno desenvolvimento da personalidade; família sem necessário casamento, pautada na igualdade entre os filhos e entre os genitores. Em todos os lares onde houver pessoas ligadas, seja por laços de sangue ou não, unidas pelo afeto, pelo plano de concretização das aspirações de cada uma delas e daquele 
núcleo como um todo, concatenadas e organizadas econômico e psicologicamente, haverá uma família. (2015, p. 155.).

Sem perder de vista a justiça pretendia e a segurança necessária, a proposta aqui apresentada se vale tanto da análise dos valores sociais circundantes como do juízo de realidade que se faz das situações concretas. Assim, aponta-se para três liames, cumulativos, nesta ocasião estabelecidos para se apurar a existência ou não de entidade familiar; quais sejam: a) afetividade; b) agrupamento por laços de casamento, união estável, sociedades de fato (famílias plurais), por descendência e/ou ascendência e, mesmo por afinidade social; e, por fim, c) dependência, que se desdobra em sentimental ${ }^{3}$, que se perfaz pelo envolvimento recíproco assentado em razões subjetivas, a exemplo das demonstrações de amor, carinho, atenção, conflitos interpessoais, preocupação, bem-estar e cuidado; e dependência material, que pode ser absoluta, relativa ou mútua. É absoluta quando um familiar mantém, de maneira exclusiva, dependência com um ou mais familiares. É relativa quando um familiar, que apesar de produzir certa riqueza ou auferir determinada renda, ainda se mantém parcialmente dependente de um ou mais familiares; e é mútua quando não há dependência material de forma absoluta e nem relativa, mas sim união de esforços econômicos e financeiros, independente de quem contribua mais ou perceba maior renda.

Quanto ao critério agrupamento, necessário outros esclarecimentos. Primeiro, a comprovação deste liame pode ser feita por meio de instrumento solene ou não, a exemplo do casamento civil, da declaração pública (certidão lavrada em Cartório de Registro de Notas) ou particular de união estável, ou ainda contrato de sociedade de fato, levado ou não a registro. $\mathrm{Na}$ ausência destes documentos, a prova pode ser testemunhal aliada a outras de conteúdo material que possam comprovar o agrupamento familiar, a exemplo de despesas, contas, transferências, mensagens telefônicas, troca de e-mails, etc. Enfim, diferentes meios probatórios admitidos em processo. Segundo, o agrupamento requer estabilidade e ostensividade, que pode se processar num plano físico, quando os grupos dividem o mesmo espaço para fins de moradia, ou mesmo no plano abstrato, porém, neste caso, a ideia de agrupamento ganha outra tonalidade, vez que, no mínimo deve haver a concorrência de interesses afins, ou seja, de construção de planos e projetos de vida em comum. Esta situação

\footnotetext{
${ }^{3}$ A dependência sentimental aqui ressaltada nada tem a ver com as afetações psicossomáticas ou de ordem psicótica que possam trazer prejuízos ao bem-estar físico e/ou mental das pessoas. Não se trata deste tipo dependência patológica, mas das sensações e reações da natureza do homem, que o estimulam enquanto sujeito autônomo e que, a partir de processos de interação e de identificação buscam aproximá-lo de seus pares por afinidades e congruência de interesses num ritmo cadenciado de envolvimentos sentimentais.
} 
pode acontecer no caso de um casal que se conheceu virtualmente e passa a se envolver à distância, utilizando a internet como ferramenta de comunicação e aproximação. A estabilidade é a permanência, a duração da relação familiar que necessariamente deve se processar num enredo espaço-tempo. Já a ostensividade é a notoriedade que deve ser levada ao conhecimento de terceiros para fins de publicização da facticidade, seja ela social ou jurídica, da relação familiar.

Sobre a possiblidade de formação de laços por afinidade social através de relação parafamiliar, tal hipótese é viável, mas calcada em interpretação cuidadosa. É que para a configuração destas propostas de famílias, faz-se necessário o preenchimento dos liames acima citados, mas por não haver o affectio maritalis, porque este liame não é de sua natureza, a demonstração da afetividade, a fraternal, por exemplo, vai exigir apuração mais rigorosa e que dependerá da análise de cada caso ${ }^{4}$. Uma saída, calcada na autonomia privada, seria o registro de contrato de sociedade de fato enquanto possibilidade jurídica para dar maior segurança à existência das relações parafamiliares. Via de regra, estas relações não se equiparam à entidade familiar, dependendo de provas sobre os liames acima traçados para tal. Se assim não o for, qualquer um pode vir a ser ente familiar de outrem, razão pela qual se justifica a apuração mais ostensiva. De todo modo, seja qual for a hipótese de formatação familiar, elas precisam conter os elementos do negócio jurídico: existência, validade e eficácia, ainda que num plano verbal e abstrato.

Quanto à validade, o inciso III do art. 104, CC/02 5 , estabelece que o negócio jurídico também deva ter "forma prescrita ou não defesa em lei". No que toca as novas propostas de famílias, se este inciso for levado ao "pé da letra", muitas serão tidas por inválidas. Para estes casos, resta, então, o trabalho hermenêutico, a flexibilizar e adequar o rigor da literalidade do inciso em comento.

\footnotetext{
${ }^{4}$ De forma muito tímida, o Projeto de Lei ${ }^{\circ}$ 2.285/2007 (Estatuto das Famílias), em seu art. 69, prevê possibilidades de famílias destituídas do affectio maritalis. O rol estabelecido não corresponde, necessariamente, às relações parafamiliares. Também, entende se tratar de rol meramente exemplificativo, dependendo da análise de cada caso para fins de apuração da existência ou não de entidade familiar, levando em conta o critérios (liames) aqui propostos. Art. 69. As famílias parentais se constituem entre pessoas com relação de parentesco entre si e decorrem da comunhão de vida instituída com a finalidade de convivência familiar. $\S 1^{\circ}$ Família monoparental é a entidade formada por um ascendente e seus descendentes, qualquer que seja a natureza da filiação ou do parentesco. $\S 2^{\circ}$ Família pluriparental é a constituída pela convivência entre irmãos, bem como as comunhões afetivas estáveis existentes entre parentes colaterais.

${ }^{5}$ Art. 104. A validade do negócio jurídico requer: I - agente capaz; II - objeto lícito, possível, determinado ou determinável; III - forma prescrita ou não defesa em lei.
} 
Apesar da dificuldade de se apurar o conteúdo do afeto, ele é uma diretriz informadora a preencher toda e qualquer espécie de entidade familiar. $\mathrm{O}$ afeto, seja qual for sua essência (marital, fraternal), é sentimento inserto nas relações familiares, em maior ou menor intensidade. Isto se dá porque as relações familiares não são sempre "um mar de rosas", pois, da própria afetividade, por ser marcada pela proximidade e mesmo pela intimidade, pode advir dissabores, angústias e problemas familiares em geral. O ambiente familiar é espaço de comunicação no qual pode emergir amor e ao mesmo tempo pode gerar desconforto emocional. Sobre o afeto, Fiuza anota que

\begin{abstract}
A afetividade, embora mereça atenção jurídica, não é norma, mas fato que pode estar presente nas relações familiares, digo "pode", porque o afeto num sentido positivo (amor, carinho) nem sempre será presença constante no seio familiar. Lá podem imiscuir-se sentimentos de ódio, inveja e desamor, tão graves quanto os de amor. Uma família normal é um conglomerado de seres humanos, na melhor das hipótese neuróticos, que podem se amar e se odiar com a mesma intensidade. Podem fazer-se bem, mas podem fazer-se muito mal. [...] Transformar um sentimento em norma é algo, senão inviável, indesejável. É exigir que todo ser humano seja perfeito ao conduzir seus sentimentos. O legislador não deve entrar nessa esfera íntima, a não ser para coibir a violência e abusos. (2015, p. 1190).
\end{abstract}

De fato, a estrutura familiar não é um todo harmonioso, mas também desarmonioso, e isto não desqualifica o afeto, que pode se transformar, ou mesmo acabar. Ainda que o afeto não exista mais, a formação familiar dele partiu, encontrou em seu alento a premissa incentivadora. De tudo que foi dito, é importante considerar que é no seio familiar, com ou sem afeto, onde "melhor se desenvolve a personalidade" (FIUZA, 2015, p. 1184). É na família que se encontra a base para a formação do "ser", a lapidar as primeiras linhas para a gênese do caráter das pessoas.

Salienta-se que esta justificação sobre o afeto não quer dizer que as relações familiares não se perfaçam por laços sanguíneos ou consanguíneos, porque de fato, e de direito, assim elas se produzem e a própria Lei desta forma estabelece. Mas o caso é que, quando se amarra o afeto às relações familiares, quebra-se aquela ideia enrijecida de patrimonialidade para atribuir maior humanidade aos enlaces familiares. $\mathrm{O}$ afeto assume esta coloração, repersonaliza o que, por natureza, é personalíssimo, ainda que dele desperte sentimento que possa se estender do amor ao ódio, mas ainda assim com essência de afetividade (FIUZA; AUTOR, 2015, p. 153).

No que toca a lealdade e a fidelidade, estas estão muito mais próximas do exercício da autonomia da vontade do que da natureza normativa dos princípios. Sendo assim, não se 
tratam de princípios a nortear as relações familiares. Entende-se que lealdade e a fidelidade sejam valores a carrear a autonomia do "ser". O valor é mutável, suscetível de variabilidade de conteúdo a depender do espaço-tempo em que se processa. Desta ideia decorre a lealdade e a fidelidade. Ora, o fato de o esposo ter uma amante não importa em deslealdade, se dessa infidelidade a esposa toma conhecimento e assim aquiesce. Tampouco é infidelidade se da relação resulta comum acordo que autoriza relações sexuais com outros pessoas. São particularidades da relação, situações tratadas em sede de autonomia da vontade dos sujeitos, onde só os envolvidos é que poderão julgar a carga valorativa violada no que toca a lealdade e a fidelidade. Em ambos os casos, é a boa-fé a reger tais hipóteses. Ademais, a não observância da fidelidade, que acarreta no não cumprimento do respeito e da lealdade, não é fator suficiente para descaracterizar a formação de famílias paralelas no que tange seus efeitos sociais e jurídicos, vez que "tanto a Lei $n^{\circ} 9.278$ de $1996^{6}$, como o Código Civil não mencionam expressamente a observância do dever de fidelidade recíproca para que possa ser caracterizada a união estável" (FIUZA; AUTOR, 2015, p. 161) ${ }^{7}$.

O mesmo raciocínio direciona-se para a monogamia. Vista por muitos como um princípio a reger a entidade familiar, esta resta cambaleante, não no sentido pejorativo, mas no sentido de que cada vez mais se torna flexível e ajustável à vontade dos sujeitos. E se é flexível, então, como poderia ser princípio?

O princípio, por sua natureza, não comporta variação espaço-tempo; princípio é princípio. Sua aferição é como uma régua e suas extremidades, ou ele está num ou noutro extremo, não suporta meio termo, relativismos. Ora, toma-se como exemplo o princípio da igualdade. Igualdade é igualdade seja aqui, em outro lugar do mundo, ou em outro momento histórico. Materialmente considerado, todos são iguais. Mas o valor que se atribuiu à igualdade há duzentos anos não reflete o valor hoje designado no Brasil. O valor que se destaca à igualdade das mulheres é diferente entre os países do oriente e do ocidente. Como se vê, é o valor impresso que dá a tonalidade ao princípio, porque este, por sua natureza, não suporta oscilações. Neste sentido, Rizzato Nunes:

\footnotetext{
${ }^{6}$ Lei que regulamenta a união estável entre homem e mulher. Art. $1^{\circ}$ É reconhecida como entidade familiar a convivência duradoura, pública e contínua, de um homem e uma mulher, estabelecida com objetivo de constituição de família. Art. $2^{\circ}$ São direitos e deveres iguais dos conviventes: I - respeito e consideração mútuos; II - assistência moral e material recíproca; III - guarda, sustento e educação dos filhos comuns.

${ }^{7}$ Também os autores anotam ponderação pertinente sobre a hostilização jurídica que se faz sobre a infidelidade, vista enquanto fato gerador de um pânico moral a abalar a estrutura social e a ordem moral (2015, p. 162).
} 
É preciso deixar clara uma distinção entre princípio e valor, para buscar eliminar a confusão que se faz entre os conceitos na linguagem jurídica corrente. Com efeito, têm-se usado os dois termos indistintamente, como se tivessem o mesmo conteúdo semântico. Mas o fato é que, enquanto o valor é sempre um relativo, na medida em que vale, isto é, aponta para uma relação, o princípio se impõe como um absoluto, como algo que não comporta qualquer espécie de relativização. O princípio é, assim, um axioma inexorável e que, do ponto de vista do Direito, faz parte do próprio linguajar desse setor de conhecimento. Não é possível afastá-lo portanto. O valor sofre toda a influência de componente histórico, geográfico, pessoal, social, local etc. e acaba se impondo mediante um comando de poder que estabelece regras de interpretação - jurídicas ou não [...]. O princípio, não. Uma vez constatado, impõese sem alternativa de variação. $(2002$, p. 05).

Por esta "lógica do razoável" é que a monogamia não pode ser princípio. Se assim é recepcionada pelo universo do Direito, é muito mais por conta de uma moral religiosa do que por critérios hermenêuticos. Justamente por esta capacidade de adequação, a depender do crivo de apreciação acordado pelo ajuste de vontades dos sujeitos envolvidos, está mais próxima de um valor do que de um princípio. "Elevar a monogamia à categoria de princípio é perpetuar o que o texto constitucional não disse; é vendar os olhos para inúmeras realidades familiares; é perseguir resultados desastrosos; é negar o reconhecimento e proteção a diversos núcleos familiares" (FIUZA; AUTOR, 2015, p. 166).

\section{OS EFEITOS PATRIMONIAS NOS NOVOS MODELOS FAMILIARES}

Diante das novas formulações de famílias é que surgem indagações sobre as uniões paralelas que se perfazem sob a estampa do repúdio social e do olhar transversal dos Tribunais. É que, muitas vezes embaraçadas por interpretações conservadoras, várias relações familiares, que se ajustam a ideia de união estável, mas que, por se processarem paralelamente às uniões consideradas moralmente aceitas, deixam de ser reconhecidas, perdendo, assim, o resguardo jurídico merecido. O Superior Tribunal de Justiça, assim vem se mantendo, praticamente vedando os olhos e ignorando estes modelos estruturais de família que se organizam simultaneamente às relações ditas solenes, formalizadas ou aceitas por uma moral social comum.

A insistente posição do Superior Tribunal de Justiça, em evocar a fidelidade como requisito à configuração ou caracterização da união estável e repudiar o reconhecimento de eventuais relações estáveis paralelas, fundamentando seus julgados em valores morais que não correspondem ao pulsar dos anseios do homem contemporâneo, parece revelar sua crença de que a família e, consequentemente, toda a sociedade, estaria sob premente ameaça. (FIUZA; AUTOR, 2015, p. 163). 
Encampadas sobre a denominação de concubinato $^{8}$, muitas são as uniões evidentemente estáveis, mas que por restrição legal, são impedidas de se ajustar aos contornos normativos do Direito. Têm repercussão no plano fático, mas inibidas quando da conversão para a esfera jurídica, seja porque não contemplam a exigência legal ${ }^{9}$, seja por conta de interpretação ainda amarrada aos construtos morais sociais de família sólida, que já não se perfazem mais.

Indubitavelmente, às uniões estáveis paralelas restam direitos patrimônios advindos, seja pela sucessão por morte, seja pela dissolução do vínculo. O olhar impuro que reina na interpretação não pode ser óbice para o resguardo dos direitos ali adquiridos. O Direito não pode marginalizar tais relações a ponto de descartá-las enquanto fato social efetivamente realizável e estanque na sociedade pós-moderna. Isto acontece porque, muitas vezes, é associada às uniões paralelas os casos de impedimento para o casamento, previstos no art. 1.521 , do $\mathrm{CC} / 02^{10}$, o que gera desconforto jurídico decorrente do prévio juízo de valor tendencioso que se lança sobre essas uniões.

De fato, não se cogita discussões aqui sobre as uniões incestuosas deste artigo, cuja linha tênue margeia entre o imoral e o amoral. A relação incestuosa, evidentemente, assusta e causa repulsa social. O Direito Pátrio não abraça, e nem poderia, a possibilidade destes tipos de "uniões paralelas". E quando se diz que não abraça é porque mesmo o Direito Brasileiro é restrito ao mensurar qualquer antijuridicidade para tais hipóteses. Assim, nem o Direito Civil, nem o Direito Penal as especificam expressamente enquanto tipicidades, em razão da total aversão social e moral que despertam. Por se tratar de cenário tão hediondo, as hipóteses incestuosas (e também o inciso VII) não são o objeto deste trabalho.

Contudo, há de se falar da possibilidade de uniões advindas da vedação do inciso VI, que ao proibirem de se casar as pessoas casadas, estende tal vedação às hipóteses de uniões paralelas que podem se formar. Com efeito, o que se analisa são estas entidades familiares

\footnotetext{
${ }^{8}$ Esta denominação por si só já é pejorativa, razão pela qual passará a ser chamada a partir de agora de união paralela, ainda que a Lei Civil faça uso da nomenclatura "concubinato".

9 Art. 1.727, CC/02. As relações não eventuais entre o homem e a mulher, impedidos de casar, constituem concubinato.

${ }^{10}$ Art. 1.521. Não podem casar: I - os ascendentes com os descendentes, seja o parentesco natural ou civil; II - os afins em linha reta; III - o adotante com quem foi cônjuge do adotado e o adotado com quem o foi do adotante; IV - os irmãos, unilaterais ou bilaterais, e demais colaterais, até o terceiro grau inclusive; V - o adotado com o filho do adotante; VI - as pessoas casadas; VII - o cônjuge sobrevivente com o condenado por homicídio ou tentativa de homicídio contra o seu consorte.
} 
plurais, que encontram esbarro legal e jurídico-interpretativo. Uniões que podem se formatar em diversos enredos, seja porque o companheiro já é casado, seja porque, ainda que não seja casado, já está em união estável com outrem.

Em sede de julgamento do (RE) 397762/2008, o STF pacificou entendimento de que a "concubina" não tem direito à divisão de pensão por morte. No caso, o falecido era casado e vivia maritalmente com a esposa, com quem teve filhos, mas manteve relação paralela, por mais de trinta anos, tendo tido outros filhos desta relação. A Corte foi taxativa ao inibir os efeitos patrimoniais à união paralela com base no rigor do parágrafo $3^{\circ}$, art. 226 , da $\mathrm{CF} / 88^{11}$.

Para o relator, Ministro Marco Aurélio, em razão da vedação legal do Código Civil aliada ao tratamento constitucional da matéria, não poderia ser considerada união estável a relação ente o falecido e a convivente, que nos seguintes termos se manifestou:

[...] para ter-se como configurada a união estável, não há imposição da monogamia,
muito embora ela seja aconselhável, objetivando a paz entre o casal. Todavia, a
união estável protegida pela ordem jurídica constitucional pressupõe prática
harmônica com o ordenamento jurídico em vigor. Tanto é assim que, no artigo 226
da Carta da República, tem-se como objetivo maior da proteção o casamento. [...] O
reconhecimento da união estável pressupõe possibilidade de conversão em
casamento. O reconhecimento da união estável entre o homem e a mulher como
entidade familiar, devendo a lei facilitar sua conversão em casamento, direciona à
inexistência de obstáculo a este último. A manutenção da relação com a autora se fez
à margem e diria mesmo mediante discrepância do casamento existente e da ordem
jurídica constitucional. (BRASIL, 2008).

A possibilidade de se reconhecer a união como entidade familiar e seus respectivos efeitos patrimoniais, pressupõe, para o Ministro, a possibilidade de conversão em casamento. Verdadeira interpretação a acarretar engessamento social das relações privadas.

Ainda que evidente o forte envolvimento entres os companheiros, o Ministro ponderou que o falecido era o chefe da família oficial e vivia com sua esposa, razão pela qual “[...] não surte efeitos jurídicos ante a ilegitimidade, ante o fato de o companheiro haver mantido o casamento com quem contraíra núpcias e com quem tivera onze filhos. [...] No caso, vislumbrou-se união estável quando, na verdade, verificado simples concubinato, conforme pedagogicamente previsto no artigo 1.727 do Código Civil” (RE, 2008, p. 617, $618)$.

\footnotetext{
${ }^{11}$ Art. 226. A família, base da sociedade, tem especial proteção do Estado. $\S 3^{\circ}$ Para efeito da proteção do Estado, é reconhecida a união estável entre o homem e a mulher como entidade familiar, devendo a lei facilitar sua conversão em casamento.
} 
Em voto divergente e vencido, o Ministro Carlos Ayres Britto acertadamente ponderou que o amparo constitucional tem previsão num todo maior em capítulo próprio da Constituição (Capítulo VII - Da Ordem Social) e sua amplitude abraça a família, criança, adolescente e o idoso. "Capítulo que tem um denominador comum, ou um mesmo fio condutor, que é tratar dos quatro temas por modo protetivo. Tutelar" (grifos no original) (RE, 2008, p, 621).

Nesta linha, o Ministro justifica que cada um destes temas se conectam, de modo a referenciarem-se sob a forma de vasos comunicantes, e prossegue ao dizer que "o hermeneuta não tem como fugir do imperativo de que ao capítulo constitucional em causa é de ser conferido o máximo de congruente unidade" (grifos no original) (RE, 2008, p. 622). E conclui, "Estou a dizer: não há concubinos para a Lei Mais Alta do nosso País, porém casais em situação de companheirismo. Até porque o concubinato implicaria discriminar os eventuais filhos do casal, que passariam a ser rotulados de "filhos concubinários"” (RE, 2008, p. 628-629).

Com interpretação diversa, em recurso de Apelação Cível no 70022775605 tramitado no TJ/RS fora determinado a partilha de bens e pensionamento em processo de reconhecimento de união estável paralela ao casamento e, posteriormente, paralela à outra união estável.

\footnotetext{
A prova dos autos é robusta e firme a demonstrar a existência de união estável entre a autora e o réu em período concomitante ao seu casamento e, posteriormente, concomitante a uma segunda união estável que se iniciou após o término do casamento. Caso em que se reconhece a união dúplice. Precedentes jurisprudenciais. Os bens adquiridos na constância da união dúplice são partilhados entre a esposa, a companheira e o réu. Meação que se transmuda em "triação", pela duplicidade de uniões. O mesmo se verificando em relação aos bens adquiridos na constância da segunda união estável. Eventual período em que o réu tiver se relacionado somente com a apelante, o patrimônio adquirido nesse período será partilhado à metade. Assentado o vínculo familiar e comprovado nos autos que durante a união o varão sustentava a apelante, resta demonstrado os pressupostos da obrigação alimentar, quais sejam, as necessidades de quem postula o pensionamento e as possibilidades de quem o supre. Caso em que se determina o pagamento de alimentos em favor da ex-companheira (grifos nossos). (BRASIL, 2008).
}

Sob outra conotação jurídica, o STJ aponta para interpretações amparadas no dever obrigacional de reparar a "concubina" pelos serviços domésticos prestados durante a vigência da relação extraconjugal. É neste sentido que a Corte vem se posicionando em alguns julgados (RE no 303.604 - SP, 2003, p. 1), retirando a matéria da alçada do Direito de Família e tangenciando-a para a esfera do Direito das Obrigações. 
Em que pese o malgrado hermenêutico, ao atribuir indenização a título compensatório à "concubina", o STJ pode até imprimir valoração à celeuma, mas, em verdade, de forma minimalista e com certo olhar conservador e transversal, exerce ato interpretativo desarrazoado ao promover absurda sub-rogação de direitos, isentado o caso da aplicação do Direito de Família. Verdadeira peripécia exegética que, em palavras comuns denotam traduzir: "não podemos reconhecer o que você pleiteia, mas se serve de consolo, resta uma indenização para lhe compensar os serviços domésticos prestados durante esses $\operatorname{anos} " 12$. Da ementa se extrai que:

Pacífica é a orientação das Turmas da $2^{\text {a }}$ Seção do STJ no sentido de indenizar os serviços domésticos prestados pela concubina ao companheiro durante o período da relação, direito que não é esvaziado pela circunstância de ser o concubino casado, se possível, como no caso, identificar a existência de dupla vida em comum, com a esposa e a companheira, por período superior a trinta anos. Pensão devida durante o período do concubinato, até o óbito do concubino. (BRASIL, 2003).

A defesa que se traz à baila é a do exercício das liberdades de escolha dos sujeitos envolvidos no enredo familiar. Ao direito, resta o importante papel de disciplinar, por meio de normas abstratas, o conteúdo jurídico, sem que dessa regulação nasça projetos moldadores de conduta ou de comportamento. Como dito, não se está a apoiar anarquismos, mas postura jurídica que permita o livre fluxo das relações familiares; claro que disto resulta a funcionalidade da norma-padrão, a promover leitura geral mediante normas programáticas, isto é, a nortear comportamentos que abraçam a dignidade da entidade familiar num sentido amplo. É neste sentido de realização material que o Código Civil pode se encaixar na proposta de democracia e de comunicação de interesses que pairam sobre uma sociedade aberta.

Nesta vazão interpretativa é que os valores sociais circundantes passam a atuar, por meio da repercussão/impacto que causam no meio e da realidade fenomênica apreendida, fornecendo critérios (liames) para apuração da configuração ou não de entidade familiar. Disto não resulta parametrização, frisa-se, porque os critérios propostos estão sustentados em metodologia axiológica, por tal, não são passíveis de enraizamento, vez que suscetíveis às variações do contexto espaço-tempo.

A abordagem dos liames para a formação das novos arquétipos familiares teve como idealização o cenário atual, marcado pela liquidez e pela velocidade. De outra banda, apesar

\footnotetext{
${ }^{12}$ Pede-se vênia, nesta passagem, pelo senso comum da abordagem, mas é que a violência simbólica praticada pelo Poder Judiciário, em alguns decisões, vai na contramão do clamor social, que reivindica posicionamentos mais ajustados à realidade dos fatos.
} 
de não serem fixos, são importantes para fins de direcionamento dos pressupostos apuradores de um arranjo mínimo, e também necessário, de uma entidade familiar; que hoje, se mostra tão multifacetada. Assim, fazem-se funcionais em razão das intensas mudanças sociais que podem apontar para produtos familiares inconsistentes, e disto resulta anarquismo.

Como se nota, a finalidade dos critérios (liames) apresentados não é fomentar qualquer tipo de fechamento operacional. Por sua natureza, não engessam, ou, se o fazem, é o mínimo possível, vez que estão calcados em valores circundantes e na realidade fenomênica social na forma como se apresenta e como se inclina para os novos modelos familiares.

\section{CONCLUSÃO}

Quanto à formação dos novos modelos familiares, não se está querendo afirmar que o Estado não deva disciplinar. Disto resulta um equívoco, porque por disciplinar pode-se entender o estabelecimento de regras que se apresentam como diretrizes a nortear as relações humanas; já a ingerência é efetivamente uma interferência estatal que através de regras dita comportamentos, parametriza condutas e engessa as relações sociais, provocando verdadeiro cerceamento da autonomia da vontade ante enredos tão humanos e existenciais, a exemplo das formações familiares.

O que se observa é quase uma espécie de autoritarismo estatal a dominar (manipular) a autonomia da vontade em frontal colisão às liberdades e às escolhas de projetos de vida dos indivíduos. O Estado tem o dever de disciplinar, mas não de exercer intervenção. Todavia, a disciplina não significa criar norma-padrão para cada configuração familiar que possa eventualmente se apresentar. Isto seria algo irrealizável e despiciente. Para os enlaces humanos que envolvem a afetividade, o Estado precisa deixá-los correr naturalmente, respeitando o fluxo da dinâmica social e existencial do homem; a disciplina, neste sentido, é restrita e ao mesmo tempo abstrata; logo, sua presença deveria ser mínima.

Neste passo, a ideia que se apoia em relação às novas formatações familiares é em prol de uma disciplina pautada por regras que resguardam os valores sociais de ordem pública, bom convívio e de natureza humana e digna, proporcionando às pessoas o livre exercício de suas escolhas (o "ser-aí" no mundo).

O próprio Código Civil peca pelo excesso de conteúdo ao regrar os direitos de família e sucessório. A Lei, ao invés de exercer tamanho intervencionismo na autonomia da 
vontade dos sujeitos, poderia balizar-se, como já o faz em outras passagens, por meio de conteúdos amplos, a exemplo das cláusulas gerais e dos conceitos jurídicos indeterminados. Nesta perspectiva é preciso sopesar valores circundantes, analisar as peculiaridades de cada caso, refletir em torno dos juízos de valor e de realidade a fim de apontar resposta jurídica afinada com a regra e ajustada com a mutabilidade intrínseca dos fatos sociais; principalmente estes, de ordem tão existencial e que permeiam as relações pessoais em sua mais pura privacidade e densa intimidade.

Ora, as relações familiares se apresentam de forma sui generis, por serem manifestações fisiopsíquicas imbuídas de maior subjetivismo, numa carga muito mais sensível do que as outras relações privadas previstas no Código Civil. Toma-se o Direito Obrigacional e o Direito Real, que representam ligações das pessoas com objetos (contratos e bens). Ainda que haja a feição subjetiva da autonomia da vontade aí envolvida, certa tonalidade objetiva deve pairar para regular estas situações. O poder de escolha dos sujeitos para estes direitos precisa convergir com regras de disciplina jurídica mais concretas para se chegar a resultado determinado. Já o direito de família se apresenta num fluxo mais contínuo, etéreo. São relações que necessariamente se passam entre os interesses dos sujeitos envolvidos. Não se trata de uma objetivação que encerra numa coisificação, no sentido de enrijecer as relações familiares, como se a elas fosse possível imputar isso. A parametrização destas relações acarreta num círculo hermenêutico hermético a estatuir verdadeiro fechamento operacional redutor das opções de escolha e dos projetos de enredos familiares que podem ser frutificados.

Não se está querendo dizer que as relações familiares devam caminhar rumo à liberdade absoluta, descambando numa libertinagem e descompromisso, ou mesmo num desrespeito, entre as pessoas e seus sentimentos. Não se trata de anarquia familiar. Tampouco pretende-se descartar a norma-padrão e sua pertinente contribuição jurídica. Mas parte-se da defesa de norma cujo conteúdo seja mais abstrato para as relações familiares. Norma que discipline, mas não determine; que intencione, mas não manipule; que direcione, mas não condicione os projetos de vida das pessoas. Enfim, que não pretenda parametrizar, ditando o que é certo ou o que é errado, mas que estabeleça cláusulas gerais sobre dignidade, solidariedade, respeito e bom convívio no âmbito familiar.

\section{REFERÊNCIAS}


ABEL, Theodore. Os fundamentos da teoria sociológica. Tradução de Christiano Monteiro Oiticica. Rio de Janeiro: Zahar Editores, 1972.

ALEXY, Robert. Teoria da Argumentação Jurídica. Tradução de Zilda H. S. Silva. São Paulo: Landy, 2005.

ALEXY, Robert. Colisão de direitos fundamentais e realização de direitos fundamentais no estado de direito democrático. Revista de Direito Administrativo, Rio de Janeiro, n. 217, jul./set. 1999.

AMARAL, Francisco. Direito Civil: introdução. 6a ed. Rio de Janeiro: Renovar, 2006.

ARENDT, Hannah. A condição humana. Tradução de Roberto Raposo. 9a ed. Rio de Janeiro: Forense Universitária, 1999.

ARONNE, Ricardo. Direito civil-constitucional e a teoria do caos: estudos preliminares. Porto Alegre: Livraria do Advogado, 2006.

ATIENZA, Manuel. As razões do direito: teorias da argumentação jurídica. São Paulo: Landy Editora, 2006.

AZEVEDO, Álvaro Villaça. Bem de Família: com comentários à Lei 8.009/90. $5^{\text {a }}$ ed. São Paulo: Revista dos Tribunais, 2002.

BAUDRILLARD, Jean. Simulacros e simulação. Tradução de Maria João da Costa Pereira. Lisboa: Relógio D’Água, 1991.

BAUMAN, Zygmunt. Modernidade líquida. Tradução de Plínio Dentzien. Rio de Janeiro: Jorge Zahar Editor, 2001.

BOBBIO, Norberto. O positivismo jurídico: lições de filosofia do direito. Tradução de Márcio Pugliesi. São Paulo: Ícone, 1995.

BOLWERK, Aloísio A; LORENTINO, Sérgio Augusto Pereira. O direito civil sob a ótica pós-positivista: uma nova interpretação a partir da redefinição do conceito de liberdade. In: Roberto Senise Lisboa; Joyceane Bezerra de Menezes (Org.). Relações privadas e democracia. $1^{\text {a }}$ ed. Florianópolis: FUNJAB, 2014, p. 125-142.

BRASIL. Constituição (1988). Constituição da República Federativa do Brasil 1988. Organizado por Angher, Anne Joyce. 20a ed. São Paulo: Rideel, 2015.

BRASIL. Lei $\mathbf{n}^{\mathbf{0}}$ 10.216, de 06 de abril de 2001. Disponível em <http://www.planalto.gov.br/ccivil_03/leis/LEIS_2001/L10216.htm>. Acesso em: 23 out. 2015.

BRASIL. Lei $\mathbf{n}^{\circ}$ 9.278, de 10 de maio de 1996. Disponível em <http://www.planalto.gov.br/ccivil_03/leis/L9278.htm>. Acesso em: 15 set. 2016. 
BRASIL. Superior Tribunal de Justiça. Recurso Especial 303.604 - SP. Relator: Aldir Passarinho - Quarta Turma. Diário de Justiça Eletrônico, Brasília, 26 mar., 2003. Disponível em: tj.jusbrasil.com.br/jurisprudencia/7159232/recurso-especial-resp-440118-rs2002-0066901-7/relatorio-e-voto-12880477. Acesso em: 18 set. 2016.

BRASIL. Supremo Tribunal Federal. Recurso Extraordinário 397762-2008/BA. Relator: Marco Aurélio. Diário de Justiça Eletrônico, Brasília, 12 set. de 2008. Disponível em: $<$ http://www.stf.jus.br/portal/processo/verProcessoAndamento.asp?numero=397762\&classe $=$ RE\&origem=AP\&recurso=0\&tipoJulgamento=M>. Acesso em: 11 set. 2016.

BRONZE, Fernando José. Lições de introdução ao Direito. Coimbra: Coimbra Editora, 1994.

CABRAL, Érico de Pina. A “autonomia” no direito privado. In: Revista de Direito Privado. São Paulo: Revista dos Tribunais, 83-129, jul/set 2004.

CHUEIRI, Vera Karam de. Filosofia do direito e modernidade: Dworkin e a possibilidade de um discurso instituinte de direitos. Curitiba: J. M, 1995.

CITTADINO, Gisele. Pluralismo, direito e justiça distributiva. $4^{\mathrm{a}}$ ed. Rio de Janeiro: Lumen Juris, 2009.

DWORKIN, Ronald. Levando os direitos a sério. Tradução de Nelson Boeira. São Paulo: Martins Fontes, 2011.

FACHIN, Odília. Fundamentos de metodologia. 5a ed. São Paulo: Saraiva, 2005.

FARIAS, Cristiano Chaves de; ROSENVALD, Nelson. Direito civil: teoria geral. $8^{\text {a }}$ ed. Rio de Janeiro: Lumen Juris, 2009.

FERRAZ JR., Tercio Sampaio. Introdução ao estudo do direito: técnica, decisão, dominação. $2^{a}$ ed. São Paulo: Atlas, 1994.

FIUZA, C. A. C.; BOLWERK, Aloísio A. A interpretação do direito civil sob a ótica póspositivista. In: Elcio Nacur Rezende; Otavio Luiz Rodrigues Junior; José Sebastião de Oliveira (Org.). Direito civil contemporâneo. 1ed. Florianópolis: CONPEDI, 2015, v. 1, p. 100-120.

FIUZA, César. Perigos de uma hermenêutica civil-constitucional. Revista da Faculdade Mineira de Direito, v. 11, n. 22, p. 65-75, $2^{\circ}$ sem. 2008.

FIUZA, César. Crise e interpretação no Direito civil da escola da exegese à teoria da argumentação. Direito Civil: Atualidades. Belo Horizonte: Del Rey, 2006.

FIUZA, César (Org.). Autonomia privada: direitos da personalidade. Belo Horizonte: D’Plácido, 2015. 
FIUZA, César. Direito civil: curso completo. $18^{\mathrm{a}}$ ed. São Paulo: Revista dos Tribunais, 2015.

FIUZA, César; AUTOR. Famílias plurais o direito fundamental à família. Revista da Faculdade de Direito da UFMG, n. 6, p. 151-180, jul./dez. 2015.

FOUCAULT, M. A hermenêutica do sujeito: curso dado no Collège de France (19811982). São Paulo: Martins Fontes, 2006.

GADAMER, Hans-Georg. Hermenêutica em retrospectiva. Heidegger em retrospectiva. Tradução de Marco Antônio Casanova. Petrópolis: Vozes, 2007.

GAGLIANO, Pablo Stolze e PAMPLONA FILHO, Rodolfo. Novo Curso de Direito Civil. $4^{a}$ ed. São Paulo: Saraiva, 2003.

GALUPPO, Marcelo Campos. A epistemologia jurídica entre o positivismo e o póspositivismo.Disponívelem:<http://webdav.sistemas.pucminas.br:8080/.../338466_A\%20epist emologia\%20j>. Acesso em: 20 abr. 2013.

GALUPPO, Marcelo Campos. O Direito Civil no contexto da superação do positivismo jurídico: a questão do sistema. Disponível em <http://books.google.com.br/books?isbn=8573086025>. Acesso em 13 de maio de 2013.

GONDIM, Elnôra; RODRIGUES, Osvaldino Marra. John Rawls e a justiça como equidade: algumas considerações. Disponível em:

<http://www.ufpi.br/subsiteFiles/parnaiba/arquivos/files/rd2ano1_artigo08_Elnora_Gondim.P DF>. Acesso em: 10 jul. 2014.

GONTIJO, Lucas de Alvarenga. Filosofia do direito: metodologia jurídica, teoria da argumentação e guinada linguístico-pragmática. Belo Horizonte: Arraes, 2011.

GOLDSTEIN, Rebecca. Incompletude: A prova e o paradoxo de Kurt Gödel. São Paulo: Companhia das Letras, 2008.

GRAU, Eros Roberto. O direito posto e o direito pressuposto. São Paulo: Malheiros, 1996.

GUERRA FILHO, Willis Santiago (coord.). Dos direitos humanos aos direitos fundamentais. Porto Alegre: Livraria do Advogado, 1997.

HÄBERLE, Peter. Hermenêutica Constitucional - A sociedade aberta dos intérpretes da constituição: contribuição para a interpretação pluralista e "procedimental" da constituição. Porto Alegre: Sergio Antonio Fabris Editor, 2002.

HABERMAS, Jürgen. Direito e Democracia: entre facticidade e validade. Vol. I. Col. Biblioteca Tempo Universitário, 101. Rio de Janeiro: Tempo Brasileiro, 1997.

HEIDEGGER, Martin. Ser e Tempo. Parte I. Petrópolis: Vozes, 1995. 
KANT, Immanuel. Fundamentação da metafísica dos costumes. Tradução de Guido Antônio de Almeida. São Paulo: Discurso Editorial: Barcarolla, 2009.

KELSEN, Hans. Teoria Pura do Direito. Tradução de João Baptista Machado. $6^{\mathrm{a}}$ ed. São Paulo: Martins Fontes, 1998.

KROHLING, A. A busca pela transdisciplinaridade nas ciências humanas. Revista de direitos e garantias fundamentais. Vitória, ES, n 2, p. 193-212, 2007.

LIPOVETSKY, Gilles. O império do efêmero: a moda e seu destino nas sociedades modernas. Tradução de Maria Lucia Machado. São Paulo: Companhia das Letras, 1989.

MARTINS-COSTA, Judith; BRANCO, Gerson. Diretrizes teóricas do novo Código Civil brasileiro. São Paulo: Saraiva, 2002.

MARTINS-COSTA, Judith. O Direito Privado como um "sistema em construção": as cláusulas gerais no Projeto do Código Civil brasileiro. Disponível em:https://www2.senado.leg.br/bdsf/bitstream/handle/id/383/r139-01.pdf?sequence=4. Acesso em 08 fev. 2015.

NERY JÚNIOR, Nelson; ROSA Maria de Andrade. Novo Código Civil e Legislação Extravagante Anotados. $1^{a}$ ed. São Paulo: Revista dos Tribunais, 2002.

PERELMAN, Chaïm. Lógica Jurídica: nova retórica. Tradução de Verginia K. Pupi. São Paulo: Martins Fontes, 2000.

RAMOS, Carmem Lucia Silveira; TEPEDINO, Gustavo et al (Orgs.). Diálogos sobre o Direito Civil - Construindo a racionalidade contemporânea. Rio de Janeiro: Renovar, 2002. RAWLS, John. Uma teoria da justiça. São Paulo: Martins Fontes, 2008.

RIO GRANDE DO SUL. Tribunal de Justiça. Processo - AC 70022775605. Relator: Rui Portanova. Porto Alegre, 19 ago., 2008. Disponível em: <http://tjrs.jusbrasil.com.br/jurisprudencia/112538623/apelacao-civel-ac-70051386100-rs/inteiro-teor112538633>. Acesso em: 17 set. 2016.

RIZZATTO NUNES, Luiz Antonio. O princípio constitucional da dignidade da pessoa humana. São Paulo: Saraiva, 2002.

SANDEL, Michael J. Justiça: o que é fazer a coisa certa. Tradução de Heloisa Matias e Maria Alice Máximo.10. ed., Rio de Janeiro: Civilização Brasileira, 2013.

SANTOS, Eduardo Rodrigues dos. O pós-positivismo jurídico e a normatividade dos princípios. Belo Horizonte: D’Plácido, 2014.

TARTURCE, Flávio. Manual de direito civil. Vol. único. São Paulo: Método, 2011.

TEPEDINO, Gustavo. O Código Civil, os chamados microssistemas e Constituição: 
premissas para uma reforma legislativa. Disponível em

<http://www.tepedino.adv.br/wp/wp-content/uploads/2012/09/biblioteca10.pdf>.

Acesso em: 18 de jun. 2014.

VIEHWEG, Theodor. Tópica e Jurisprudência: Uma contribuição à investigação dos fundamentos jurídico-científicos. Tradução de Kelly Susane Alfen da Silva. $5^{\text {a }}$ ed. Porto Alegre: Sergio Antonio Fabris Editor, 2008. 